\title{
Impedance Matching Network
}

This paper was downloaded from TechRxiv (https://www.techrxiv.org).

\section{LICENSE}

CC BY 4.0

SUBMISSION DATE / POSTED DATE

$14-01-2022$ / 22-01-2022

CITATION

Jing, Jerry (2022): Impedance Matching Network. TechRxiv. Preprint. https://doi.org/10.36227/techrxiv.18392084.v1

$\mathrm{DOI}$

10.36227/techrxiv.18392084.v1 


\title{
Impedance Matching Network
}

\author{
Jerry Jing
}

Abstract - In this report there are for matching network will be shown and there theory and coefficients will be given by me.

Index Terms - Z-parameter, S-parameter.

\section{INTRODUCTION}

In this report, four different matching network will be introduce and their value in network will be given by hand calculating and computer analysis. In the first matching network we just use inductor. In the second matching network, we just use a simple LC matching network with up-converting to match a $1 \Omega$ to $50 \Omega$. As we have learnt how to calculate the quality factor of up-converting network and the equation between quality factor, capacitor and inductor, we can easily calculate the value of them. The third matching network is the one stage lump line matching, which means we can just use the $\mathrm{LC}$ group to take the place of a single impedance matching. In this matching, as it only has one stage, it is called narrow band matching because it cannot offer a wide band. The last matching network is about the wide band matching network, because this lump line network have 5-stage, which means it can offer a large bandwidth. The concrete calculation of value in network will be given in appendix.

\section{PROCEDURE FOR PAPER SUBMISSION}

\section{A. Review Stage}

To finish the experiment, there are so many step should follow.

--First, using the theory that taught in the class to calculate the value of different element in the matching network.

--Second, set up the four different TB to verify your calculation.

--Third, using the cadence to simulation your matching network and using the calculator to test your band width, S-parameters and impedance.

\section{FIGURE}

During the experiment I get so many related graphs. They can be classified into four parts, the first one is the matching only with inductor, the second one is LC narrow band matching network, the third one is 1-stage, 5-segament matching network, the last one is 5-stage, 3-segament matching network.

First matching network:

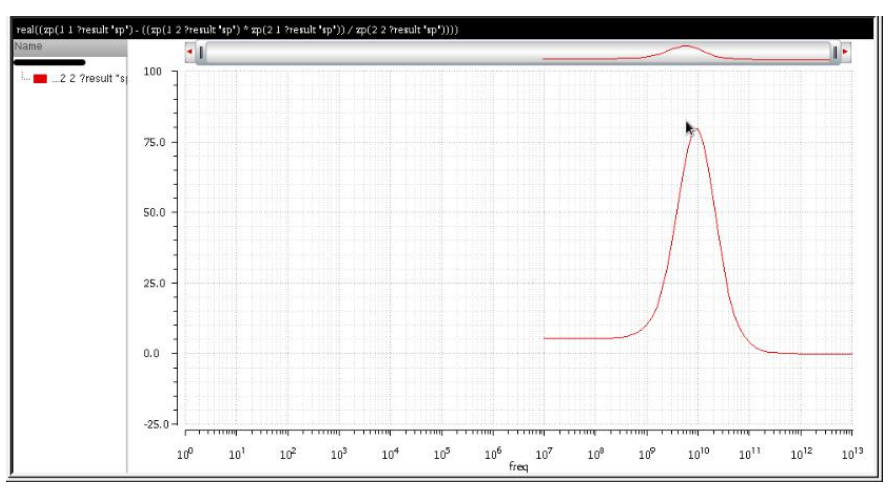

Fig. 1 This is the curve of resistance

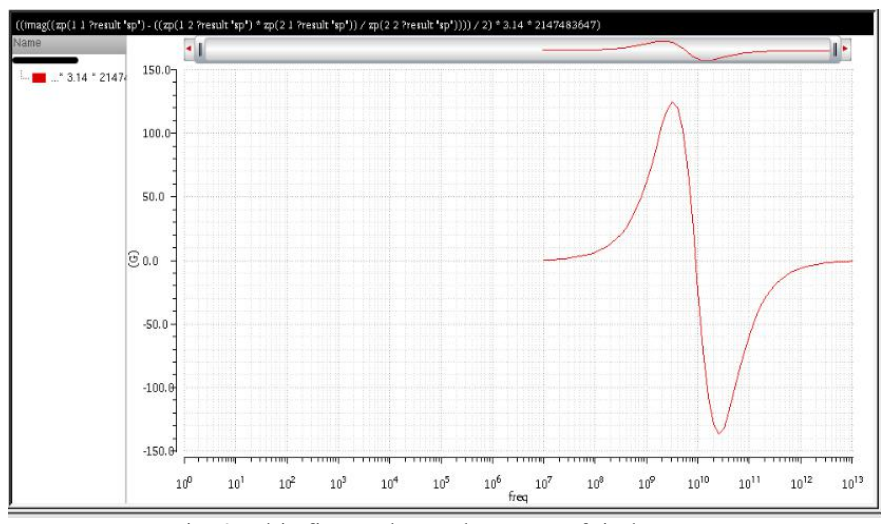

Fig. 2 This figure shows the curve of inductance

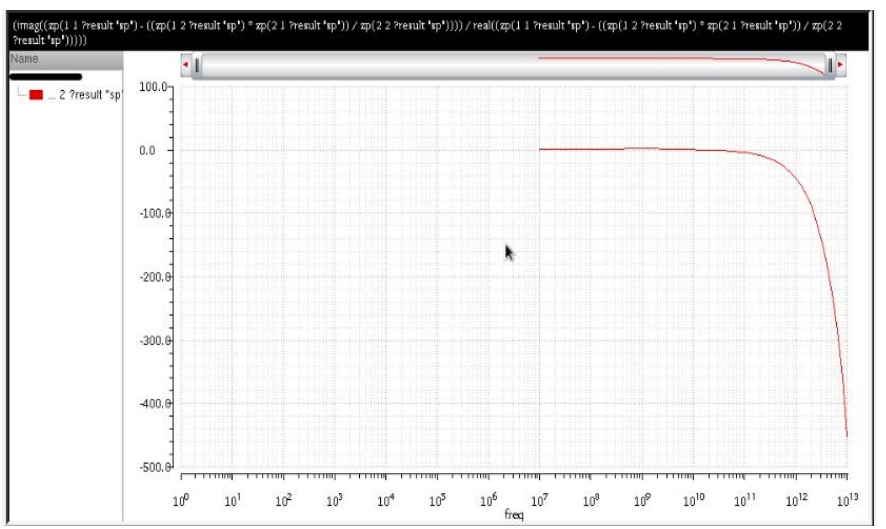

Fig. 3 This figure shows the derivation of $\mathrm{Q}$

Figure 1 to 3 shows the curve of the value of resistance, inductance and the quality factor in frequency of $10 \mathrm{GHz}$.

Second matching network: 


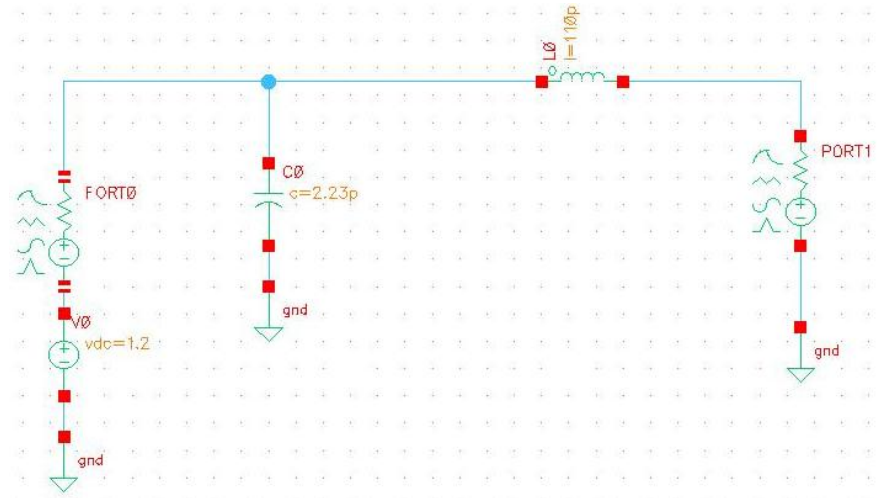

Fig. 4 The test bench of LC impedance matching

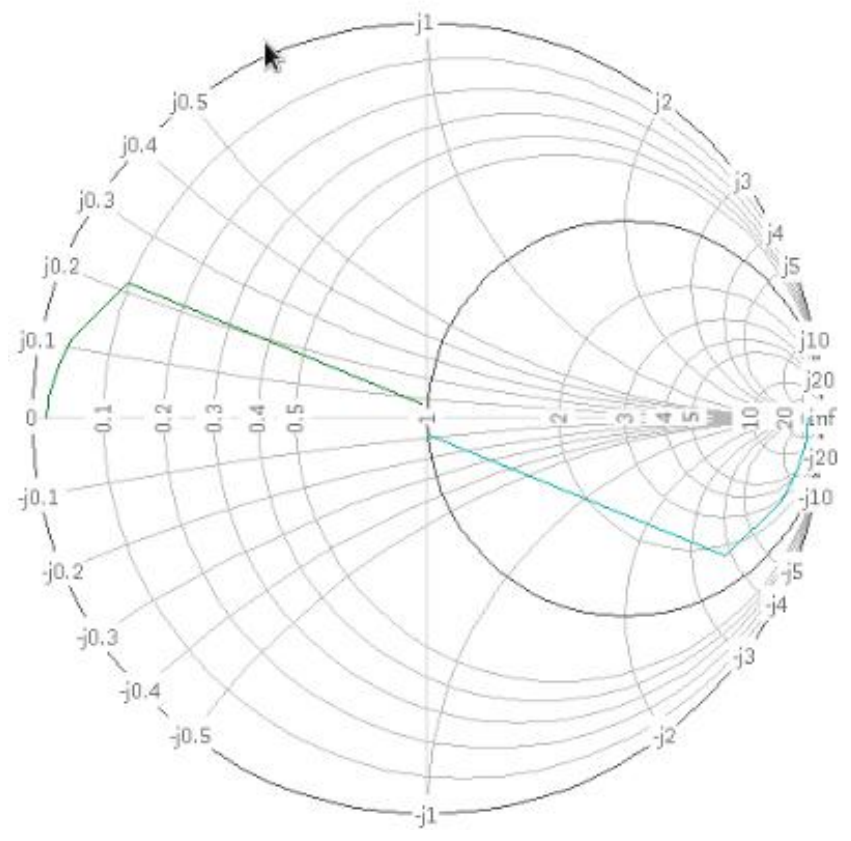

Fig. 5,6 These figures show the S-parameter for

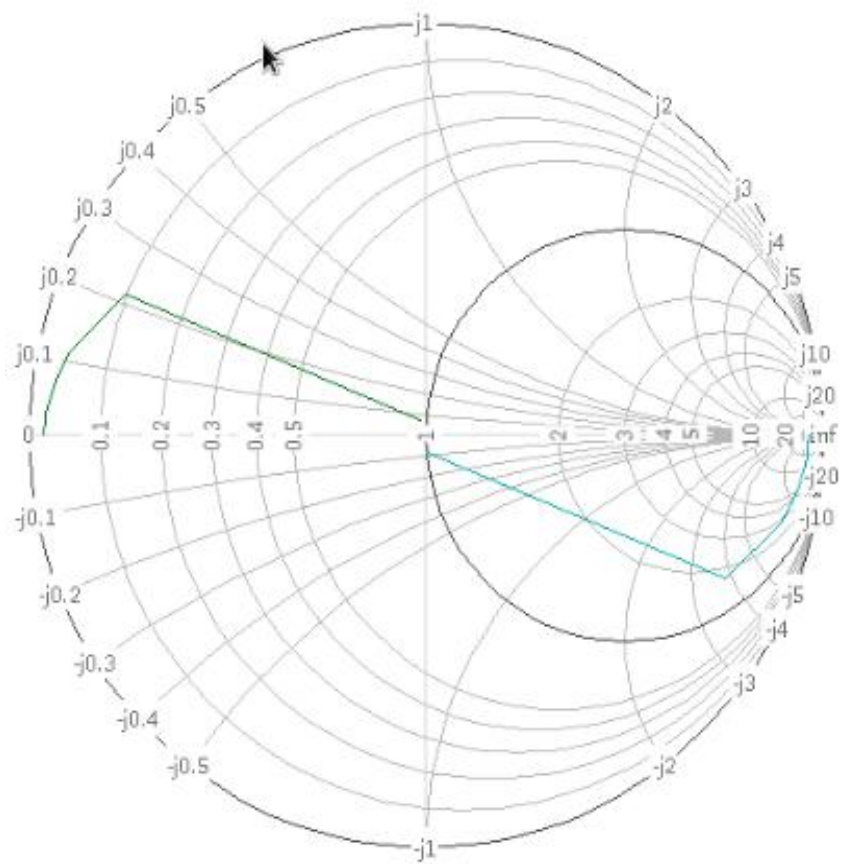

Fig. 7,8 These figures show the S-parameter for down

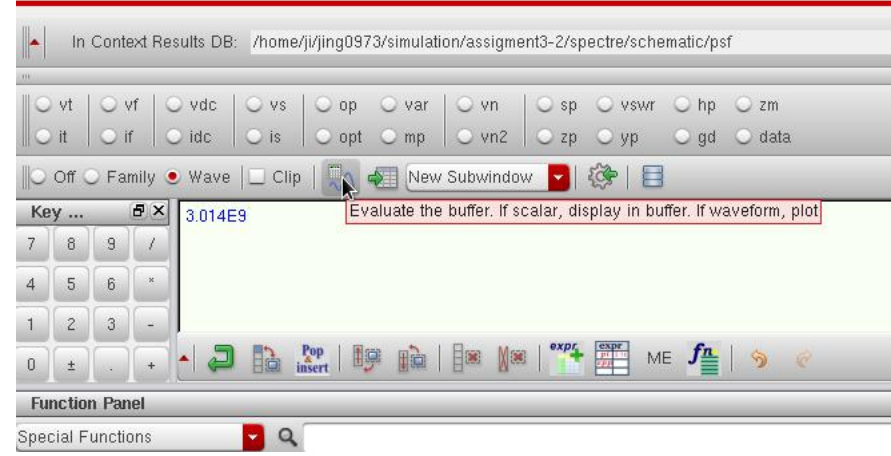

Fig. 9 This is the bandwidth

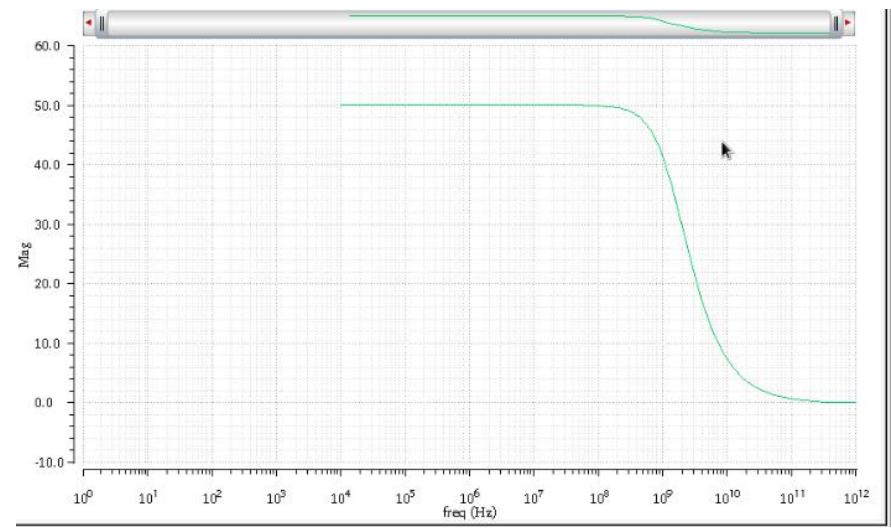

Fig. 10 This is the impedance 1

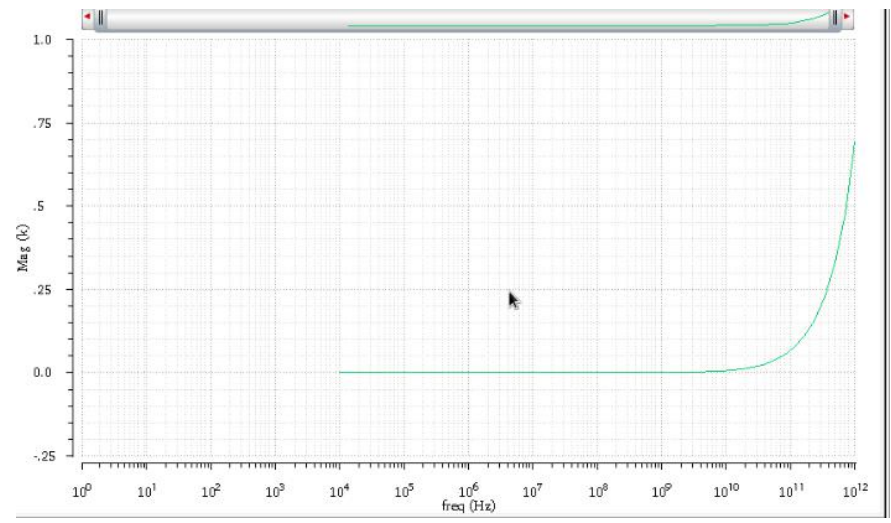

Fig. 11 This is the impedance 2

Figure 4 to 11 show up-converting and down-converting situation. Figure 5,6 show the up situation, figure 7,8 show the down situation. Figure 10 shows the up-converting impedance. Figure 11 shows the down-converting impedance.

Third matching network:

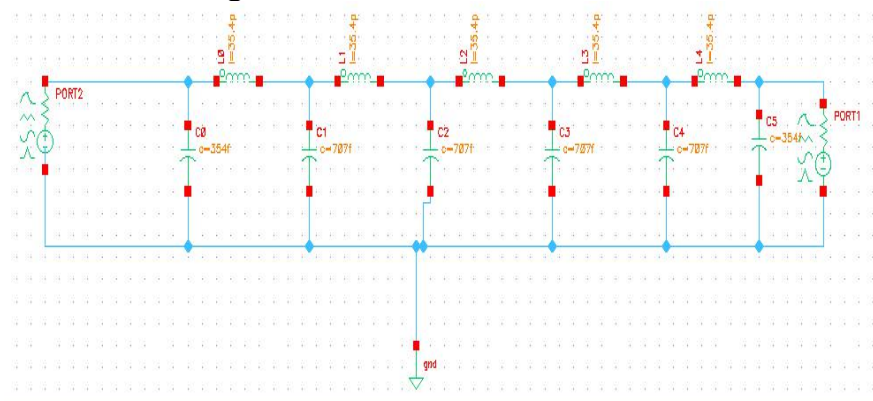

Fig. 10 Test bench 


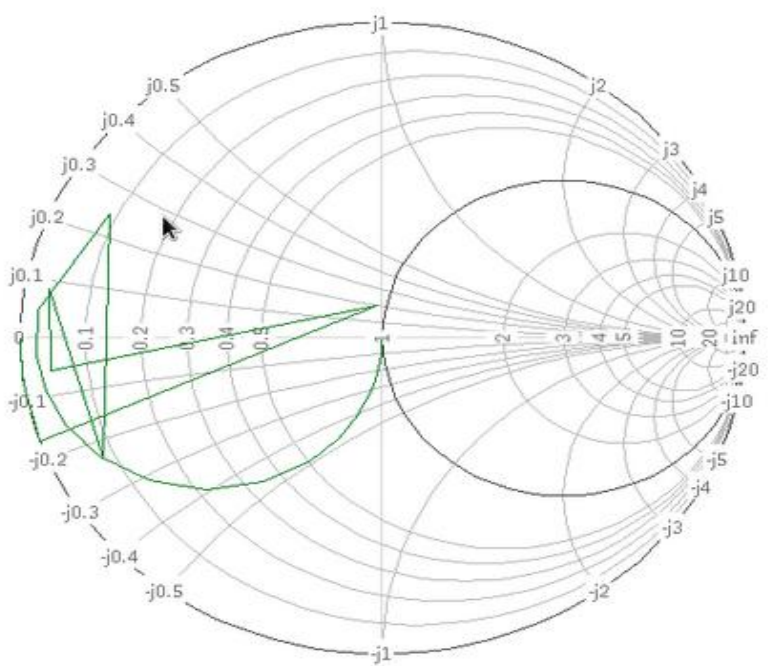

Fig. 11,12 This figure shows S-parameter

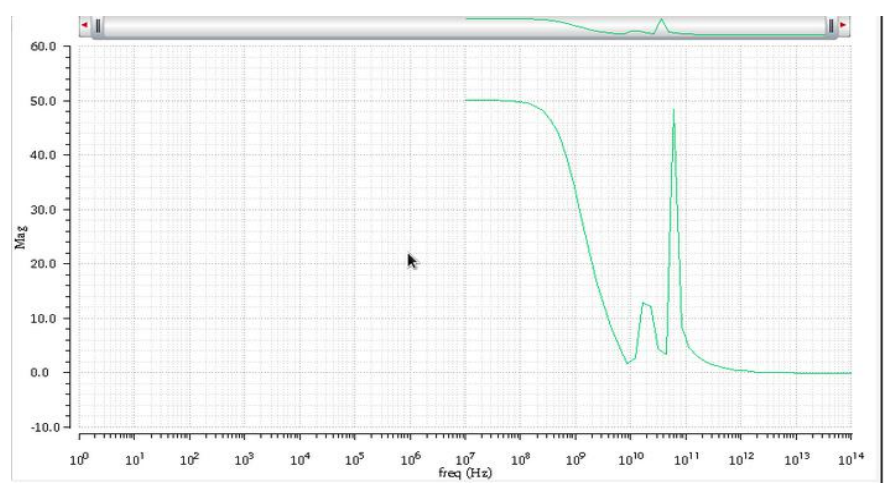

Fig. 13 This figure shows the impedance

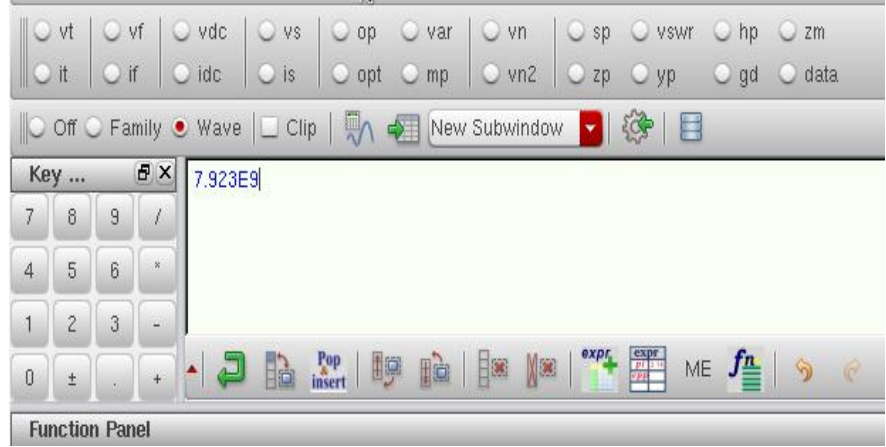

Fig. 14 This is the figure shows the bandwidth

We may easily know that this matching is about narrow band because it only have single stage.

The last matching network:

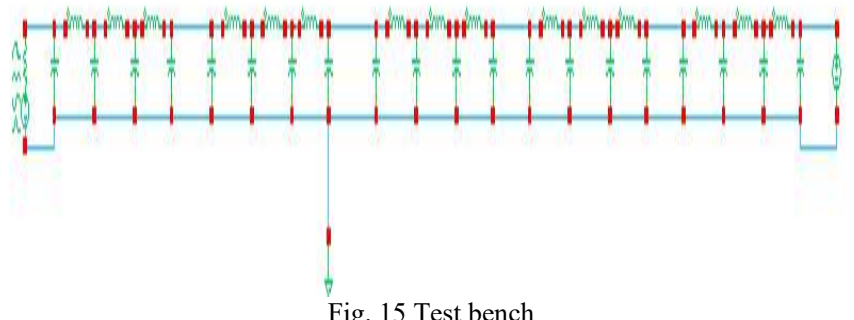

Fig. 15 Test bench

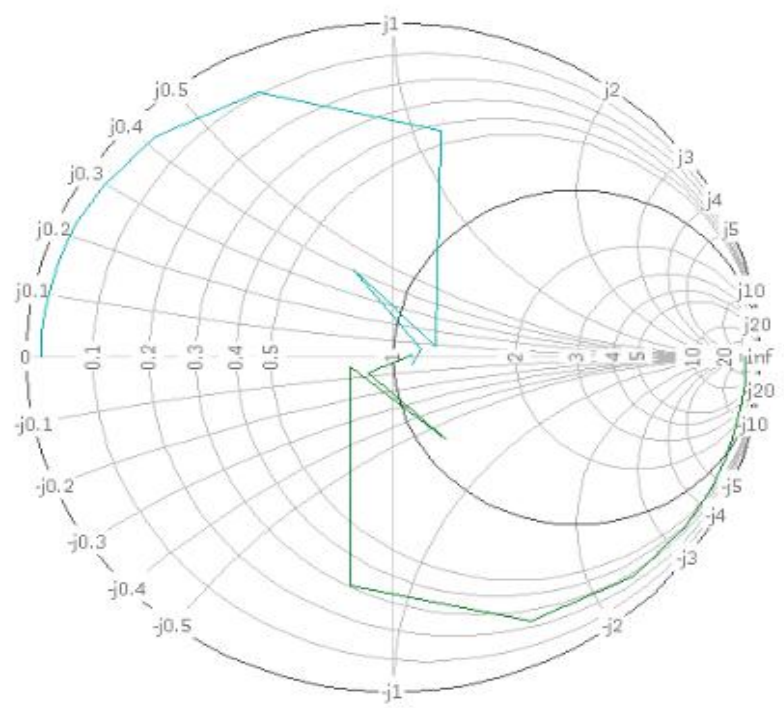

Fig. 16,17 these figures show the S-parameter

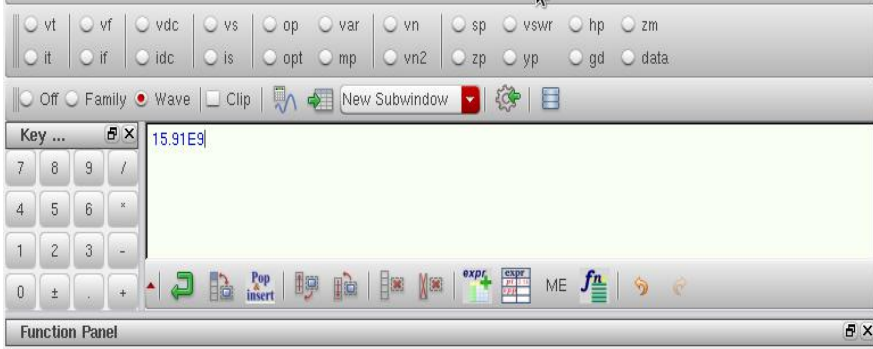

Fig. 18 This figure shows the band width

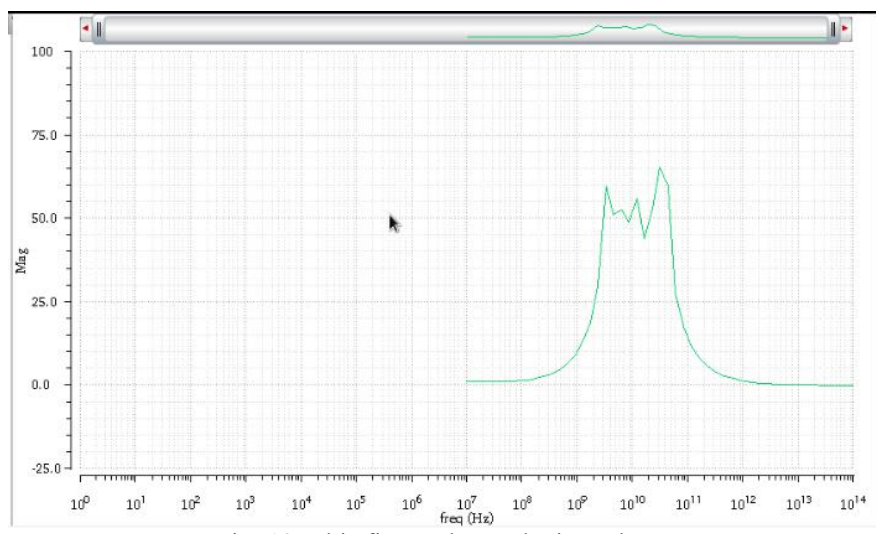

Fig. 19 This figure shows the impedance

In order to get the off current, we should set the $V_{1}$ and $V_{2}$ into required value, which means we should set to variable and then give them the exact values. Second we should set the trans time into $1 \mathrm{~nm}$ so that we can see the vary of the output. From the Figure 19 we can easily read the off current when $\mathrm{V}_{1}=0 \mathrm{~V}$ and $\mathrm{V}_{2}=1 \mathrm{~V}$.

\section{DISCUSS}

Before the experiment, I review the previous knowledge that taught in the class, I realized that this experiment is just like a verification of different matching network. This experiment is aimed to let us use the knowledge to solve a concrete problem and let us know how to connect the 
knowledge with the problem that faced in actual work.

\section{CONCLUSION}

After finish this experiment I realize that we should understand the function of different matching work so that we may use it easily in the experiment. As I haven't remember some equation in matching network, I just review the knowledge and then I can begin to do the experiment. Maybe some others learn it better than me, they may just begin the experiment without using time to review the previous knowledge.

\section{APPENDIX}

The calculation of the value in network will be given in paper by hand writing.

\section{ACKNOWLEDGMENT}

Thanks for the help from teacher, because of teaching our the way of analyzing the matching network, so that I can easily get the value in network. Thank you for the classmate because they remind me that the due day is Oct. $29^{\text {th }}$.

\section{REFERENCES}

[1] Tony Chan Carusone, David Johns, Kenneth Martin, Analog Integrated Circuit Design, $2^{\text {nd }}$ edition, international student version, 2013,pp 15-49. 